\title{
Central Nervous System Nitric Oxide Synthase Activity Regulates Insulin Secretion and Insulin Action
}

\author{
Ravi Shankar, ${ }^{\ddagger}$ Jin-Su Zhu, ${ }^{\star}$ Byron Ladd, ${ }^{\star}$ David Henry," Hua-Qiong Shen, ${ }^{\star}$ and Alain D. Baron ${ }^{\star \S}$ \\ $*$ Department of Internal Medicine, and ${ }^{\ddagger}$ Department of Pediatrics, Division of Endocrinology, Indiana University School of Medicine; \\ ${ }^{\S}$ Richard L. Roudebush VA Medical Center, Indianapolis, Indiana 46202; and ${ }^{\|}$Eli Lilly and Company, Indianapolis, Indiana
}

\section{Abstract}

Systemic inhibition of nitric oxide synthase (NOS) with $N^{\mathrm{G}}-$ monomethyl-L-arginine (L-NMMA) causes acute insulin resistance (IR), but the mechanism is unknown. We tested whether L-NMMA-induced IR occurs via NOS blockade in the central nervous system (CNS). Six groups of SpragueDawley rats were studied after chronic implantation of an intracerebroventricular (ICV) catheter into the lateral ventricle and catheters into the carotid artery and jugular vein. Animals were studied after overnight food deprivation, awake, unrestrained, and unstressed; all ICV infusion of L-NMMA or D-NMMA (control) were performed with artificial cerebrospinal fluid. ICV administration of L-NMMA resulted in a 30\% rise in the basal glucose level after $2 \mathrm{~h}$, while ICV D-NMMA had no effect on glucose levels. Insulin, epinephrine, and norepinephrine levels were unchanged from baseline in both groups. Tracer $\left({ }^{3} \mathrm{H}-3\right.$-glucose $)$-determined glucose disposal rates during $2 \mathrm{~h}$ euglycemic hyperinsulinemic $(300 \mu \mathrm{U} / \mathrm{ml})$ clamps performed after ICV administration of L-NMMA were reduced by $22 \%$ compared with D-NMMA. Insulin secretory responses to a hyperglycemic clamp and to a superimposed arginine bolus were reduced by $28 \%$ in L-NMMA-infused rats compared with D-NMMA. In conclusion, ICV administration of L-NMMA causes hyperglycemia via the induction of defects in insulin secretion and insulin action, thus recapitulating abnormalities observed in type 2 diabetes. The data suggest the novel concept that central NOS-dependent pathways may control peripheral insulin action and secretion. This control is not likely to be mediated via adrenergic mechanisms and could occur via nonadrenergic, noncholinergic nitrergic neural and/or endocrine pathways. These data support previously published data suggesting that CNS mechanisms may be involved in the pathogenesis of some forms of insulin resistance and type 2 diabetes independent of adiposity. (J. Clin. Invest. 1998. 102:1403-1412.) Key words: insulin resistance • type 2 diabetes $\bullet$ sympathetic nervous system $\bullet$ nonadrenergic noncholinergic neurotransmission $\bullet$ nitric oxide synthase

Address correspondence to Alain D. Baron, M.D., Department of Internal Medicine, Division of Endocrinology and Metabolism, 541 North Clinical Drive, CL 459, Indianapolis, IN 46202-5111. Phone: 317-274-1339; FAX: 317-278-0658; E-mail: abaron@iupui.edu

Received for publication 7 February 1998 and accepted in revised form 12 August 1998.

J. Clin. Invest.

(C) The American Society for Clinical Investigation, Inc. 0021-9738/98/10/1403/10 \$2.00

Volume 102, Number 7, October 1998, 1403-1412

http://www.jci.org

\section{Introduction}

The pathogenesis of type 2 diabetes has been extensively studied; however, the etiology of this fascinating and complex disorder of metabolism remains elusive. Because overt classical type 2 diabetes is characterized by abnormalities of $\beta$-cell function (decreased insulin secretion) (1-3), insulin action (insulin resistance) in skeletal and adipose tissue (4-6), and hepatic glucose metabolism (inappropriately elevated hepatic glucose output) (7), attention has been focused on metabolic pathways resident in these organ systems. Numerous candidate genes and their products involved in relevant metabolic pathways have been examined but with relatively modest success (8-10). While the metabolic disturbance of type 2 diabetes is striking, it is remarkable that the level of fasting hyperglycemia is relatively constant within a narrow range. Indeed, given stable nutrition and physical activity, fasting hyperglycemia varies little from day to day in patients with type 2 diabetes, suggesting that glucohomeostatic mechanisms are reset and tightly regulated at a higher glycemic level. Moreover, the level of fasting hyperglycemia in these patients is apparently sufficient to normalize the rates of peripheral tissue glucose uptake (via mass action) despite insulin resistance (11). Given that fasting hyperglycemia is largely determined by rates of hepatic glucose output $(12,13)$, it is reasonable to suspect that hepatic and peripheral tissue glucose metabolism is tightly coupled. This high degree of regulation and coordination of interorgan fuel flux suggests the presence of a complex centralized control system.

Endothelial, neuronal, and inducible nitric oxide synthases (eNOS, nNOS, and iNOS, respectively) ${ }^{1}$ are the rate-limiting enzymes in the synthesis of nitric oxide (NO), a gas with numerous properties (14), including the modulation of vascular tone, neurotransmission, and cytotoxicity, respectively. We have recently reported that acute systemic administration of high doses of $N^{\mathrm{G}}$-monomethyl-L-arginine (L-NMMA) - a competitive inhibitor of nitric oxide synthase (NOS) - in healthy, adult male Sprague-Dawley rats results in the development of marked insulin resistance and hypertension (15). Because these observations could have resulted from general inhibition of all NOS isoforms, we recently tested whether NOS activity resident in the central nervous system (CNS) plays a role in the control of hypertension and insulin sensitivity. In preliminary studies performed in anesthetized rats, we examined the

1. Abbreviations used in this paper: CNS, central nervous system; CSF, cerebrospinal fluid; EGO, endogenous glucose output; eNOS, endothelial nitric oxide synthase; GIR, glucose infusion rate; HGO, hepatic glucose output; ICV, intracerebroventricular; iNOS, inducible nitric oxide oxide synthase; L-NMMA, $N^{\mathrm{G}}$-monomethyl-L-arginine; MAP, mean arterial pressure; NANC, nonadrenergic, noncholinergic; nNOS, neuronal nitric oxide synthase; NO, nitric oxide; NOS, nitric oxide synthase; Ra, rate of glucose appearance; $\mathrm{Rd}$, rate of glucose disappearance. 
acute metabolic and pressor effects of an injection of $500 \mu \mathrm{g}$ of L-NMMA or D-NMMA (an inert isomer) into the lateral ventricle of the brain. Hypertension and hyperglycemia were observed in the animals receiving L-NMMA, while no changes in blood pressure or glycemic parameters were noted in the rats receiving D-NMMA, an inert isomer. The same dose of L-NMMA given systemically had no effect on blood pressure or insulin secretion. Thus, the data suggested that CNS NOS activity may play a role in modulating blood pressure and glucose metabolism.

The current study was conducted in chronically catheterized, awake, unstressed rats to more definitively determine if inactivation of CNS NOS can induce abnormalities in insulin action and/or insulin secretion without the confounding effects of anesthesia. Demonstration of such an effect would provide the first evidence that central NO-dependent efferent pathways may play a role in the resetting of glucohomeostatic mechanisms in insulin-resistant states and type 2 diabetes.

\section{Methods}

\section{Surgical manipulations}

Insertion of intracerebroventricular (ICV) canula. Canula for intraventricular placement were custom ordered from Plastics One Inc. (Roanoke, VA). Outer canula measuring $11 \mathrm{~mm}$ in total length, dummy canula measuring $10 \mathrm{~mm}$ in length, and infusion canula measuring $12 \mathrm{~mm}$ in length were used. Adult male rats (Harlan Sprague Dawley, Indianapolis, IN) weighing 250-300 g were used in all the experiments. After an overnight fast, the rats were anesthetized with intramuscular ketamine hydrochloride $(10 \mathrm{mg} / 100 \mathrm{~g}$; Fort Dodge Laboratories, Inc., Fort Dodge, IA) and placed on the Kopf stereotactic apparatus. An appropriate side arm holding the guide canula was attached. The vertical coordinate of the side arm was set at $0^{\circ}$ in the lateral plane and at $90^{\circ}$ in the horizontal plane. Animals were positioned appropriately on the apparatus using the head and chin holders. The scalp was incised in the midline to expose the saggital suture. The periosteum was opened and reflected away from the surgical field. The lateral, anteroposterior, and dorsoventral coordinates of the lateral ventricle on either side were determined from the Atlas of Paxinos and Watson (16). The bregma was used as the reference point, and a hole was drilled in the frontal bone at the junction of the lateral and anteroposterior coordinates. Extreme caution was exercised to avoid tearing the dural vessels during this process. Four smaller holes were drilled around this central hole, and stainless-steel screws were in- serted half-way through these holes. The outer guide canula was positioned over the central hole and lowered carefully until the necessary dorsoventral coordinate was reached (i.e., the tip of the outer guide canula would be in or very close to the lateral ventricle). The canula was fixed to the skull using cranioplastic cement after ensuring hemostasis. After the cement had set, the outer canula was freed from the side arm and the dummy canula or cap was inserted to close the outer canula. The rats were then allowed to recover from the anesthesia and were handled on a regular basis, with manipulation of the canula to get them accustomed to these maneuvers.

Insertion of arterial and venous catheters. Silastic catheters (ID 0.020 in $\times$ OD 0.037 in; Dow Corning, Midland, MI) were placed in the right jugular vein and polyethylene PE-50 tubing (ID 0.023 in $\times$ OD 0.038 in; Becton-Dickinson, Parsippany, NJ) was placed in the left carotid artery of the rats according to a previously described procedure 3-6 d after lateral ventricular cannulation (17). Catheters were exteriorized to the back of the neck and capped. The experimental protocols were initiated 2-3 d after cannulation of neck vessels, after overnight food deprivation.

\section{ICV infusions}

Artificial cerebrospinal fluid (CSF) was composed of $145 \mathrm{mM} \mathrm{NaCl}$, $2.7 \mathrm{mM} \mathrm{KCl}, 1.0 \mathrm{mM} \mathrm{MgCl}, 1.2 \mathrm{mM} \mathrm{CaCl}_{2}, 0.2 \mathrm{mM}$ ascorbate, $\mathrm{pH}$ adjusted to 7.3-7.4, and $2 \mathrm{mM}$ Na phosphate buffer was used as vehicle for all ICV infusion studies. Artificial CSF was freshly prepared within $48 \mathrm{~h}$ of each experiment. L-NMMA or D-NMMA was dissolved in the artificial CSF to a final concentration of $250 \mu \mathrm{g} / \mu \mathrm{l}$. A small amount of this solution was withdrawn into the internal fusion canula connected to a polyethylene supply tube with a captive collar (Plastics One Inc.) to secure the unit to the outer guide canula. This tubing was then connected to a 1-cc syringe primed with the infusate. The syringe was set into a microinfusion pump (Harvard Apparatus Inc., South Natick, MA), which was programmed to deliver $2 \mu \mathrm{l}$ of the infusion solution over $6 \mathrm{~min}(0.333 \mu \mathrm{l} / \mathrm{min})$. After an overnight fast, the rats were placed in a test cage, the dummy canula was removed, and the infusion canula was introduced into the outer guide canula and fixed in position. When fixed, the inner canula would project $1.0 \mathrm{~mm}$ from the tip of the outer guide canula and lie in the lateral ventricle. The experiments began with the simultaneous infusion of saline through the jugular vein and the test substance (L-NMMA or D-NMMA) into the lateral cerebral ventricle. The infusion canula was removed 10 min after the infusion.

At the termination of the ICV studies, green dye was infused through the ICV canula into the ventricle, and the animal was guillotined and catheter placement was visually confirmed. Only the data from animals where placement was confirmed were used in the analyses.

\section{Protocol \# 1}

Protocol \# 2

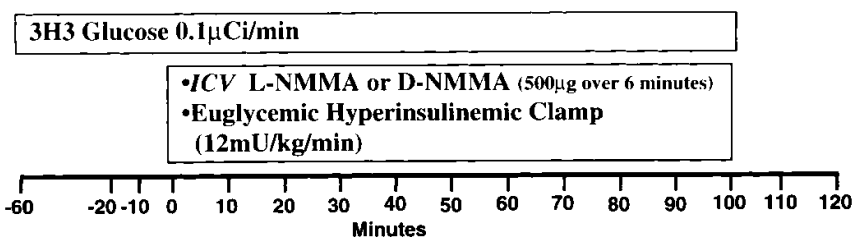

Protocol \# 3

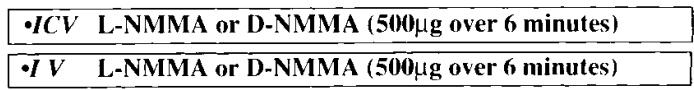

Protocol 2

Protocol \# 3

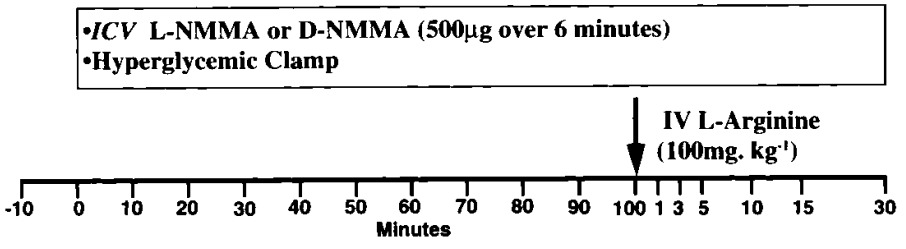

Figure 1. In each protocol, two groups of rats underwent ICV bolus injection (over $6 \mathrm{~min}$ ) of either L-NMMA or D-NMMA. Protocol 1: $(n=10$ in each group) ICV injection alone; $(n=4$ in one control group) intravenous injection of L-NMMA only. Protocol 2: ( $n=6$ in each group) ICV injection followed by $12 \mathrm{mU} / \mathrm{m}^{2} / \mathrm{min}$ euglycemic hyperinsulinemic clamp with tracer determined $\left({ }^{3} \mathrm{H}-3-\right.$ glucose) glucose turnover measurement. Protocol 3: ( $n=6$ in each group) ICV injection followed by a hyperglycemic $(\sim 280 \mathrm{mg} / \mathrm{dl})$ clamp for $100 \mathrm{~min}$. At $100 \mathrm{~min}$, insulin secretory response to a superimposed arginine bolus was measured. 

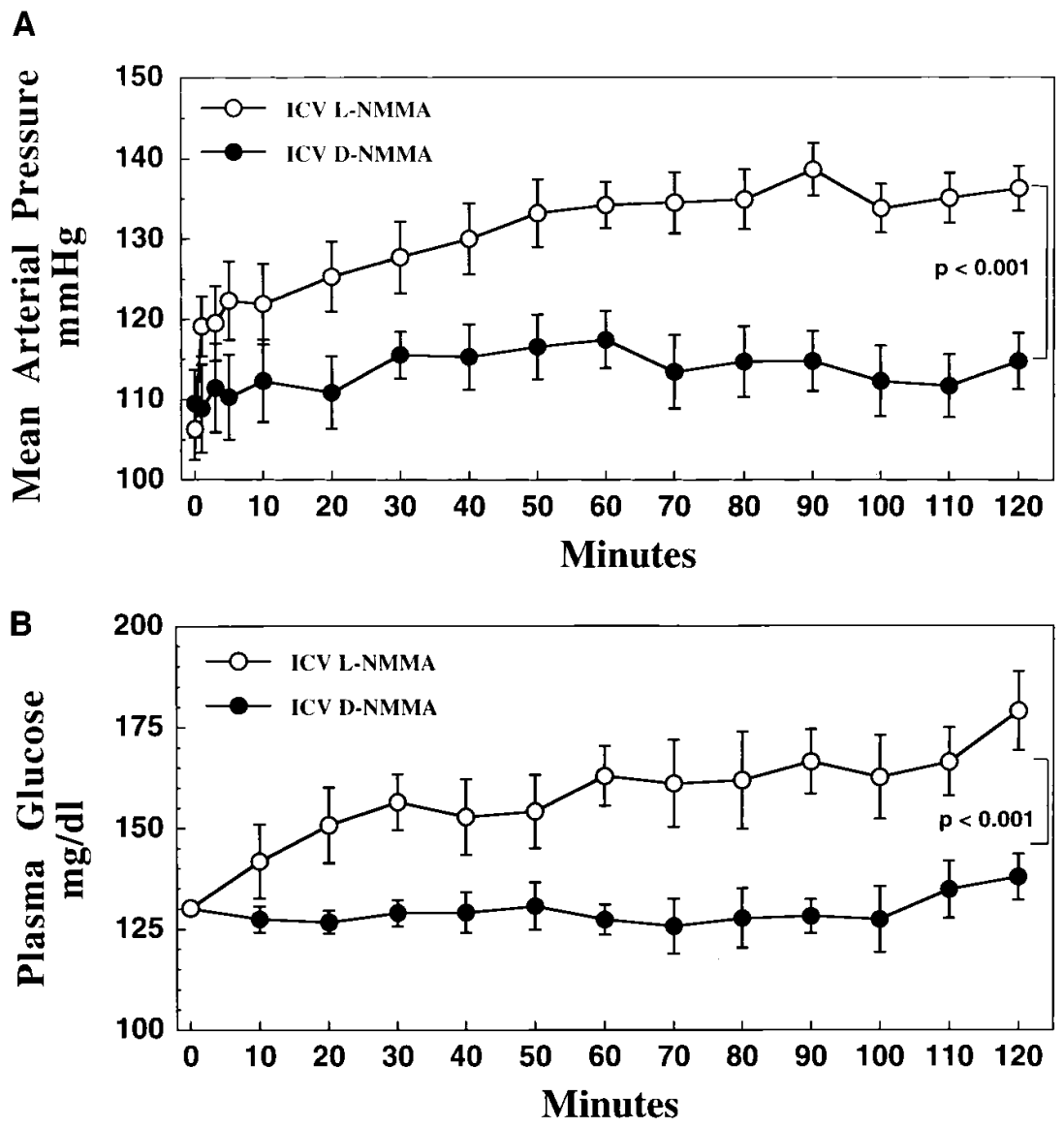

Figure 2. $(A) \mathrm{MAP}$ in rats measured at baseline and at $10 \mathrm{~min}$ intervals for $120 \mathrm{~min}$ after ICV administration of L-NMMA or D-NMMA alone (protocol 1). (B) Plasma glucose levels in rats measured at baseline and at $10 \mathrm{~min}$ intervals for 120 min after ICV administration of L-NMMA or D-NMMA alone (protocol 1).

\section{Determination of mean arterial pressure $(M A P)$}

At the onset of the study, the arterial catheter was connected to a pressure transducer linked to a custom-made invasive blood pressure monitor calibrated with a mercury column. MAP was recorded every 5-10 s over a 5-min period, and values were averaged to obtain a representative baseline value. After the ICV bolus, MAP measurement was recorded in a manner similar to that utilized at baseline at the time points described in the protocol below.

\section{Experimental protocols}

For each experimental protocol, two groups of rats were studied. One group received ICV L-NMMA, while the other received ICV D-NMMA. All studies were approved by the Indiana University/Purdue University Animal Use Committee. In Protocol 1, ten rats were studied in each group. In Protocols 2 and 3, six rats were studied in each group. Three different experimental protocols were performed.

Protocol 1: ICV L-NMMA or D-NMMA alone. These studies were performed to determine the effect of inhibition of CNS NOS on blood pressure, glucose, insulin, and catecholamine levels (Fig. 1). At baseline, two samples were obtained $10 \mathrm{~min}$ apart for determination of glucose, insulin, and catecholamine levels. A bolus of $500 \mu \mathrm{g}$ of L-NMMA or D-NMMA ( $2 \mu l$ total vol) was infused into the lateral cerebral ventricle for $6 \mathrm{~min}$, and normal saline was infused intravenously. Following the ICV bolus, glucose and blood pressure were measured every $10 \mathrm{~min}$. Insulin levels were measured at 30, 60, 90, and $120 \mathrm{~min}$ after the ICV bolus. Catecholamine levels were measured at $-10,0,90$, and 120 min after the ICV bolus. The experiment was terminated $120 \mathrm{~min}$ after the ICV bolus. To establish the specificity of the effects observed with ICV injection, another set of control

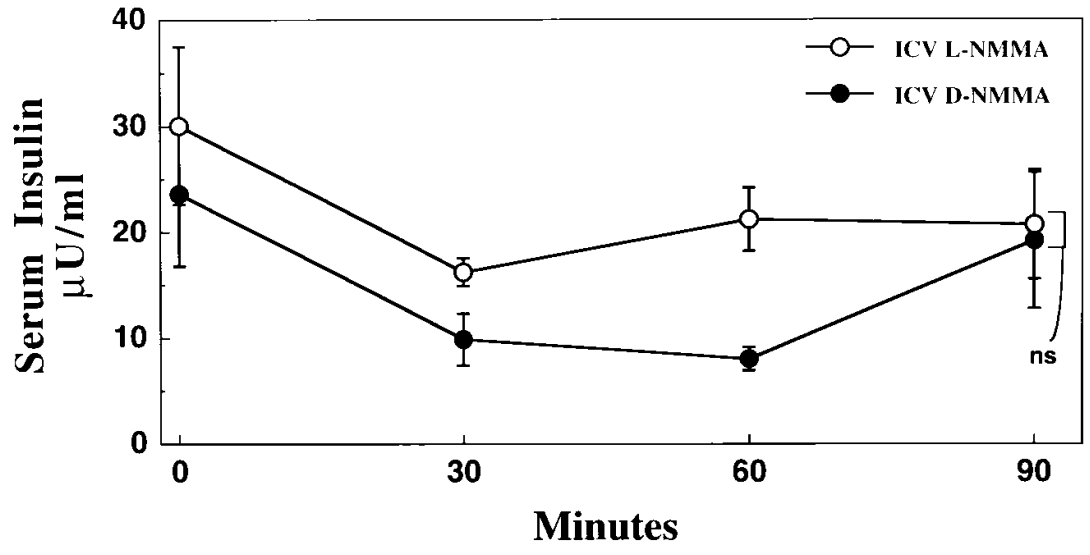

Figure 3. Serum insulin levels in rats measured at baseline and at $30 \mathrm{~min}$ intervals for $90 \mathrm{~min}$ after ICV administration of L-NMMA or D-NMMA alone (protocol 1). 


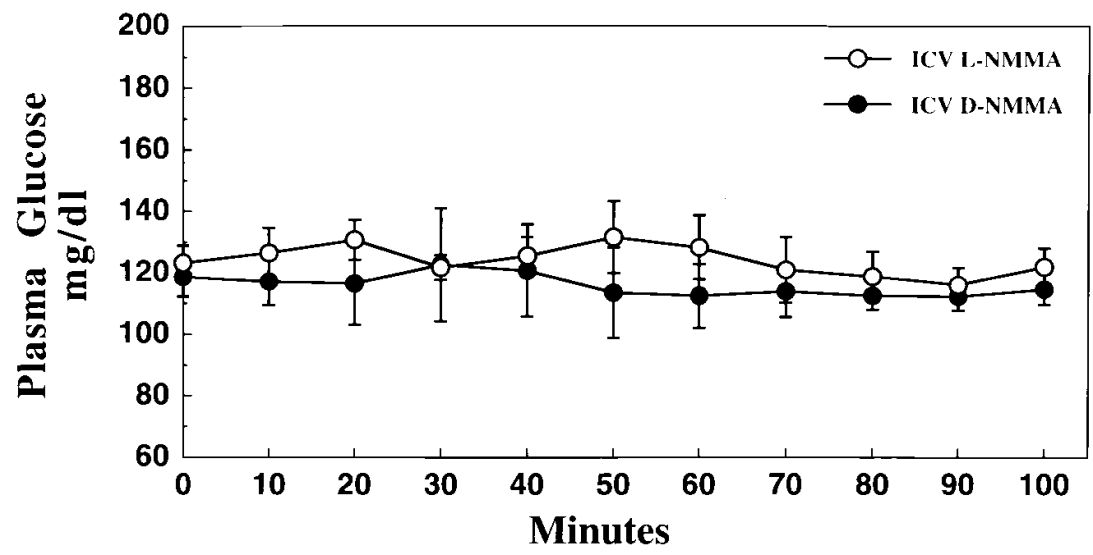

Figure 4. Plasma glucose levels in rats at baseline and during a hyperinsulinemic euglycemic clamp after ICV administration of L-NMMA or D-NMMA (protocol 2). experiments was performed by intravenous infusion of $500 \mu \mathrm{g}$ of L-NMMA for $6 \mathrm{~min}$. Plasma glucose and blood pressure were measured at baseline, at 30, 60, 90, and $120 \mathrm{~min}$.

Protocol 2: CNS NOS inhibition + euglycemic hyperinsulinemia. The effect of inactivating CNS NOS on blood pressure and insulin action in peripheral tissues was evaluated by performing euglycemic hyperinsulinemic clamps immediately following an ICV infusion of L-NMMA or D-MNNA (500 $\mu \mathrm{g})$ (Fig. 1). Euglycemic hyperinsulinemic clamp studies were performed using a modification of the method described by Smith et al. (18). Arterial and venous lines were connected to sampling and infusion syringes, respectively. Glucose turnover in both the basal and insulin-stimulated state was assessed isotopically by bolus injection of $6 \mu \mathrm{Ci}$ of $\left[3-{ }^{3} \mathrm{H}\right]$ glucose (NEN Life Science Products, Inc., Boston, MA) followed by a constant infusion at $0.1 \mu \mathrm{Ci} / \mathrm{min}$. Blood for measurement of basal glucose-specific activity was obtained after 40, 50, and $60 \mathrm{~min}$ of constant tracer infusion. Insulin infusion (Humulin-R; Eli Lilly and Co., Indianapolis, IN) was then initiated at $t=0$ of the clamp at a rate of $12 \mathrm{mU} / \mathrm{kg} / \mathrm{min}$. The insulin infusate was mixed in a heparinized ( $9 \mathrm{U} / \mathrm{ml}$ of heparin) solution of glucose tracer and blood (obtained from cardiac puncture of a littermate) drawn up into a 5-ml syringe and delivered continuously via a Compact Harvard pump (model 975; Harvard Apparatus, Inc.). Plasma glucose concentration was measured at 5-10 min intervals and clamped at euglycemia with a variable infusion of $20 \%$ dextrose solution (Abbott Laboratories, North Chicago, IL) via an adjustable pump (model A-99; Razel Scientific Instruments, Stamford, CT). Serum insulin levels were measured at $t=90$ and $100 \mathrm{~min}$ during the clamp. All clamps were carried out for $100 \mathrm{~min}$. Blood samples were obtained at $t=90$ and $100 \mathrm{~min}$ to measure steady-state glucose-specific activity during euglycemic hyperinsulinemia.

Under basal conditions and during insulin infusion, the rate of glucose appearance $(\mathrm{Ra})$ was calculated by dividing the known infusion rate of tritium counts by the glucose-specific activity. The rate of hepatic glucose output was calculated as Ra minus the glucose infusion rate $(\mathrm{HGO}=\mathrm{Ra}-\mathrm{GIR})$. Under steady-state conditions, $\mathrm{Ra}$ is equal to the rate of glucose disappearance $(\mathrm{Rd})$.

Protocol 3: CNS NOS inhibition + hyperglycemic clamp and arginine. These studies were undertaken to evaluate the effect of inhibiting CNS NOS activity on insulin secretion in response to hyperglycemia and arginine stimulation (Fig. 1). For these studies, hyperglycemic clamps were performed immediately following an ICV infusion of 500 $\mu \mathrm{g}$ of L-NMMA or D-NMMA into the lateral ventricle. After a 20-min baseline period, during which fasting glucose and insulin levels were measured in duplicate, a variable infusion of $20 \%$ dextrose solution (Abbott Laboratories) via an adjustable pump (model A-99; Razel Scientific Instruments) was used to achieve blood glucose levels of $\sim 280$ $\mathrm{mg} / \mathrm{dl}$. Plasma glucose was determined every $10 \mathrm{~min}$. When the blood glucose concentration was maintained at the desired level with minimal changes in the GIR $(<10 \%)$ for at least $30 \mathrm{~min}$, it was assumed that steady state was achieved. Steady-state GIRs were subsequently kept constant for $\sim 70-130 \mathrm{~min}$. Insulin levels were determined at 90 and $100 \mathrm{~min}$, after which a $100 \mathrm{mg} / \mathrm{kg}$ bolus of L-arginine $(100 \mathrm{mg} / \mathrm{dl})$ (Sigma Chemical Co., St. Louis, MO) was infused rapidly. Insulin and glucose levels were determined at 1, 3, 5, 10, 15, and 30 min following the arginine bolus.

\section{Analytical techniques}

Plasma glucose was determined by the glucose oxidase method with a glucose analyzer (model 2300 Stat; Yellow Springs Instruments, Yellow Springs, $\mathrm{OH}$ ). Plasma samples for determination of glucose-specific activity were processed and evaluated according to the technique previously reported $(17,18)$. Serum insulin levels were measured by double-antibody radioimmunoassay, using rat insulin antibody (Linco, St. Louis, MO). Human insulin antibody was used to measure circulating immunoreactive human insulin during the hyperinsulinemic clamp studies. Blood drawn for analysis of catecholamine levels

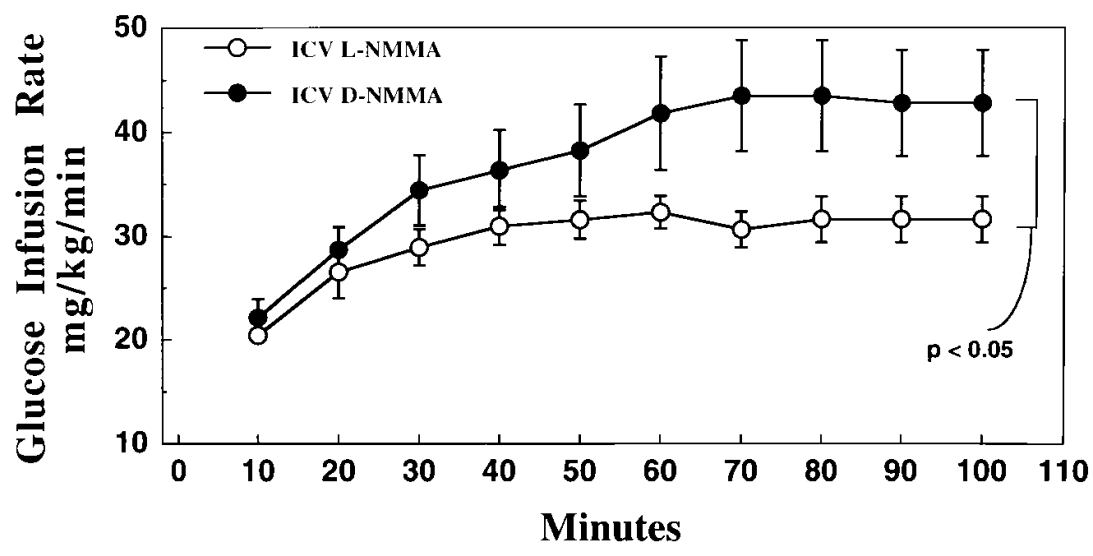

Figure 5. GIRs $(\mathrm{mg} / \mathrm{kg} / \mathrm{min})$ in rats during a hyperinsulinemic euglycemic clamp after ICV administration of L-NMMA or D-NMMA (proto$\operatorname{col} 2)$. 
Table I. Catecholamine Levels at Baseline and during ICV Administration of L-NMMA or D-NMMA Alone (Protocol 1)

\begin{tabular}{lcrc}
\hline Time $(t, \mathrm{~min})$ & L-NMMA & D-NMMA & P value \\
\hline Epinephrine $(\mathrm{pg} / \mathrm{ml})$ & & & \\
10 & $665.6 \pm 120.9$ & $1126.0 \pm 478.9$ & NS \\
0 & $779.3 \pm 206.0$ & $574.1 \pm 121.4$ & NS \\
90 & $1026.6 \pm 280.4$ & $1619.1 \pm 788.7$ & NS \\
120 & $896.0 \pm 269.7$ & $1227.0 \pm 711.2$ & NS \\
Norepinephrine $(\mathrm{pg} / \mathrm{ml})$ & & & \\
10 & $426.1 \pm 78.9$ & $625.1 \pm 143.5$ & NS \\
0 & $367.2 \pm 48.6$ & $489.7 \pm 104.8$ & NS \\
90 & $417.2 \pm 55.6$ & $941.4 \pm 404.0$ & NS \\
120 & $519.3 \pm 201.7$ & $695.8 \pm 170.7$ & NS \\
& & & \\
\hline
\end{tabular}

was immediately transferred to heparin-treated tubes set on ice and spun for $1 \mathrm{~min}$ in a $0^{\circ} \mathrm{C}$ centrifuge. The supernatant was pipetted into precooled capped tubes and stored at $-86^{\circ} \mathrm{C}$. All samples were analyzed within $3 \mathrm{wk}$ of collection as previously described (19).

\section{Statistical analyses}

All comparisons were made between L-NMMA versus D-NMMA groups, respectively, throughout the result section. All data are expressed as mean \pm SEM. Results were analyzed using the Statview 4.5 software package (Abacus Concepts, Inc., Berkeley, CA) run on a Power Macintosh 7600 computer. The two groups were compared using ANOVA followed by Fisher's protected least significant difference test or Student's $t$ test where applicable. Significance was accepted at $P<0.05$.

\section{Results}

Protocol 1: ICV L-NMMA or D-NMMA alone. Both L-NMMAand D-NMMA-treated groups exhibited similar MAP at baseline (106.3 \pm 3.8 vs. $109.5 \pm 4.2 \mathrm{mmHg}$, respectively, $P=\mathrm{NS})$. Immediately following ICV infusion of L-NMMA, MAP rose while no significant change was noted in animals infused with D-NMMA. In this latter group, MAP remained essentially unchanged from baseline throughout the study. 20 min following ICV infusion, MAP was $125 \pm 4 \mathrm{mmHg}$, or $14 \%$ higher in the L-NMMA - than in the D-NMMA-treated group, and by 120 min, MAP had stabilized to $137 \pm 3 \mathrm{mmHg}$, a level $\sim 20 \%$ higher than baseline $(P<0.001)$ (Fig. $2 A$ ). Basal plasma glucose levels were identical in both L-NMMA versus D-NMMA groups $(130.2 \pm 2.3$ vs. $130.1 \pm 2.0 \mathrm{mg} / \mathrm{dl}$, respectively) and did not change perceptibly in the animals infused with D-NMMA. In contrast, in the animals receiving ICV infusion, L-NMMA plasma glucose concentrations rose above baseline by $15 \%$ at $20 \mathrm{~min}$ and continued to rise, reaching a level of $181 \pm 6 \mathrm{mg} / \mathrm{dl}$ at $120 \mathrm{~min}$, an $\sim 30 \%$ increase above baseline $(P<0.05)$ (Fig. $2 B$ ). These glycemic and hemodynamic changes were not accompanied by any perturbation in serum catecholamine levels (Table I). At 90 and $120 \mathrm{~min}$, both plasma glucose and MAP
Table III. Characteristics of Animals at Baseline and after ICV Administration of L-NMMA or D-NMMA during Euglycemic Hyperinsulinemia (Protocol 2)

\begin{tabular}{lccc}
\hline & L-NMMA & D-NMMA & $P$ value \\
\hline$N$ & 6 & 6 & - \\
Weight $(\mathrm{g})$ & $287.2 \pm 12.6$ & $289.8 \pm 6.1$ & $\mathrm{NS}$ \\
Fasting glucose $(\mathrm{mg} / \mathrm{dl})$ & $123.3 \pm 4.5$ & $118.8 \pm 6.5$ & $\mathrm{NS}$ \\
Steady-state glucose $(\mathrm{mg} / \mathrm{dl})$ & $120.0 \pm 4.5$ & $118.5 \pm 7.4$ & $\mathrm{NS}$ \\
Fasting insulin $(\mu \mathrm{U} / \mathrm{ml})$ & $19.2 \pm 2.1$ & $11.7 \pm 2.6$ & $\mathrm{NS}$ \\
Steady-state insulin $(\mu \mathrm{U} / \mathrm{ml})$ & $313.1 \pm 73.9$ & $298.1 \pm 57.2$ & $\mathrm{NS}$ \\
Baseline MAP $(\mathrm{mmHg})$ & $112.7 \pm 3.9$ & $115.4 \pm 1.7$ & $\mathrm{NS}$ \\
Steady-state MAP $(\mathrm{mmHg})$ & $137.3 \pm 2.6$ & $129.8 \pm 2.6$ & $<0.05$ \\
Steady-state GDR $(\mathrm{mg} / \mathrm{kg} / \mathrm{min})$ & $33.9 \pm 1.8$ & $43.3 \pm 5.1$ & $<0.05$ \\
Basal HGO $(\mathrm{mg} / \mathrm{kg} / \mathrm{min})$ & $8.4 \pm 1.5$ & $8.1 \pm 0.9$ & $\mathrm{NS}$ \\
Residual HGO $(\mathrm{mg} / \mathrm{kg} / \mathrm{min})$ & $2.3 \pm 2.2$ & 0.00 & $\mathrm{NS}$ \\
& & & \\
\hline
\end{tabular}

levels were at their peak values, while catecholamine levels were unchanged from baseline. Serum insulin levels were comparable in both groups under basal conditions (30.0 \pm 7.4 vs. $23.7 \pm 6.9 \mu \mathrm{U} / \mathrm{ml}, P>0.05)$. Insulin levels fell below baseline in both groups $(P<0.05) 30 \mathrm{~min}$ after ICV injection, returning to baseline levels by 60 and $90 \mathrm{~min}$ in the L-NMMA- and D-NMMA-infused groups, respectively. At 90 min post-ICV, infusion insulin levels were unchanged from baseline and not different between L-NMMA and D-NMMA groups (Fig. 3). Because animals infused with the $\mathrm{L}$ analog displayed hyperglycemia, the lack of an appropriate rise in prevailing insulin levels suggested a defect in the insulin secretory response to glucose induced by CNS NOS blockade. In contrast to ICV administration, infusion of $500 \mu \mathrm{g}$ of L-NMMA intravenously caused no change in either plasma glucose or MAP (Table II).

Protocol 2: CNS NOS blockade and insulin action. Baseline MAP was similar in both L-NMMA- and D-NMMA-treated groups, $112.7 \pm 3.9$ versus $115.4 \pm 1.7 \mathrm{mmHg}$, respectively, $P>$ 0.05 (Table III). During hyperinsulinemia, MAP rose in both groups, but the rise was greater in the L-NMMA-treated group. Under steady-state conditions, MAP was elevated in the L-NMMA-infused group compared with the control group, $137.3 \pm 2.6$ and $129.8 \pm 2.6 \mathrm{mmHg}$, respectively, $P<0.05$ (Table III). Fasting blood glucose levels were similar in both groups $(123.3 \pm 4.5$ vs. $118.8 \pm 6.5 \mathrm{mg} / \mathrm{dl}, P=\mathrm{NS})$ and were clamped close to baseline levels during hyperinsulinemia (Fig. 4). The steady-state glucose and immunoreactive insulin concentrations in both the L-NMMA- and D-NMMA-infused groups were nearly identical $(120 \pm 4.5$ vs. $118.5 \pm 7.5 \mathrm{mg} / \mathrm{dl}$ and $313.0 \pm 73.9$ vs. $298.1 \pm 57.2 \mathrm{mU} / \mathrm{ml}$, respectively) (Table III). The GIR required to maintain euglycemia in both groups of rats was comparable initially. After $50 \mathrm{~min}$ of hyperinsulinemia, GIR was $\sim 18 \%$ lower, and by $100 \mathrm{~min}$ it was $\sim 26 \%$ lower in the rats receiving ICV L-NMMA versus D-NMMA (31.62 \pm 2.21 vs. 43.28 $\pm 5.09 \mathrm{mg} / \mathrm{kg} / \mathrm{min}, P<0.05$ ) (Fig. 5). Basal endogenous

Table II. Effects of $500 \mu \mathrm{g}$ of L-NMMA Intravenous Bolus on Plasma Glucose Levels and MAP

\begin{tabular}{lcccc}
\hline \multicolumn{1}{c}{$n=4$} & $t=0$ & $t=30$ & $t=60$ & $t=90$ \\
\hline Glucose (mg/dl) & $130 \pm 4$ & $116 \pm 7$ & $124 \pm 6$ & $119 \pm 4$ \\
MAP (mmHg) & $124.4 \pm 2.4$ & $129.3 \pm 1.7$ & $127.6 \pm 0.3$ & $131 \pm 3$ \\
& & & & $121.7 \pm 0.3$ \\
\hline
\end{tabular}




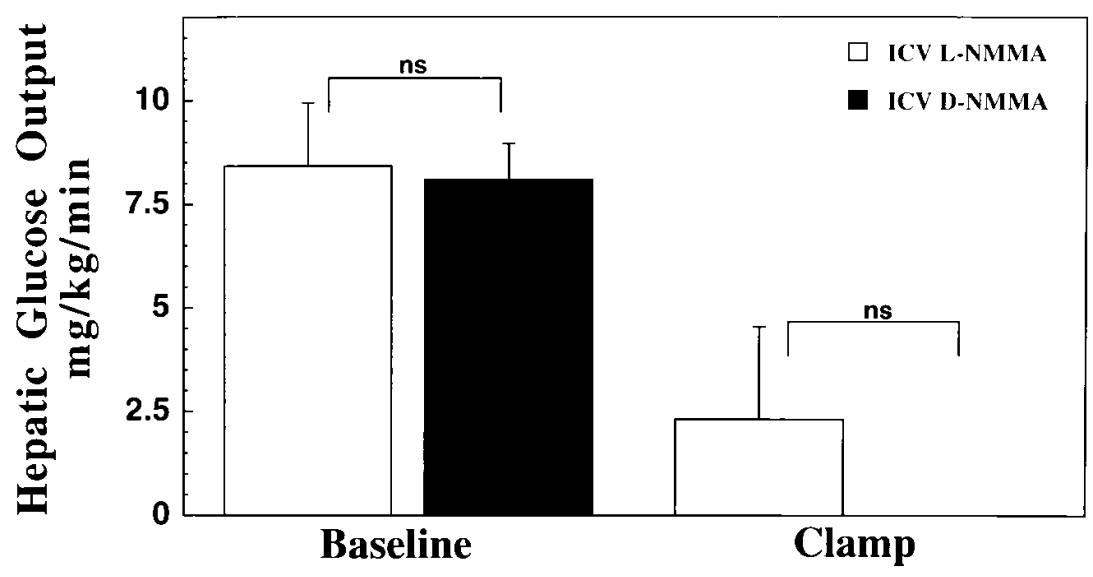

Figure 6. Rates of hepatic glucose output at baseline and during a euglycemic hyperinsulinemic clamp study after ICV administration of L-NMMA or D-NMMA (protocol 2). glucose output (EGO) was nearly identical in both groups $(8.42 \pm 1.52$ vs. $8.09 \pm 0.88 \mathrm{mg} / \mathrm{kg} / \mathrm{min}, P<0.05)$ (Fig. 6). After $100 \mathrm{~min}$ of hyperinsulinemia, EGO was completely suppressed in animals infused with D-NMMA while residual EGO $(2.31 \pm 2.33 \mathrm{mg} / \mathrm{kg} / \mathrm{min})$ was still measurable in the rats infused with L-NMMA, although not statistically different from zero. Glucose-specific activities at 80,90 , and 100 min of euglycemic hyperinsulinemia were 22,261 $\pm 1,697,23,579 \pm 2,008$, $22,880 \pm 1,973 \mathrm{dpm} / \mathrm{mg}$ in the L-NMMA-infused group and $18,569 \pm 1,247,18,114 \pm 1,120$, and $17,050 \pm 1,635 \mathrm{dpm} / \mathrm{mg}$ in the D-NMMA-infused group, indicating achievement of steady state. Isotopically determined steady-state glucose disposal rates were reduced in the animals receiving ICV L-NMMA versus D-NMMA $(33.9 \pm 1.8$ vs. $43.3 \pm 5.1 \mathrm{mg} / \mathrm{kg} / \mathrm{min}, P<0.05)$ (Table III).

Protocol 3: CNS NOS blockade and insulin secretion. Under hyperglycemic clamp conditions, steady-state glucose concentrations were nearly identical in both the L-NMMA- and D-NMMA-infused groups $(286.3 \pm 8.0$ vs. $283.0 \pm 14.8 \mathrm{mg} / \mathrm{dl}$, $P=$ NS) (Fig. 7). Steady-state insulin levels during the hyperglycemic clamp were $43.5 \pm 11.5 \mu \mathrm{U} / \mathrm{ml}$ and $59.8 \pm 18.7 \mu \mathrm{U} / \mathrm{ml}$ during L-NMMA versus D-NMMA, respectively $(P=\mathrm{NS})$. GIR required to maintain hyperglycemia were reduced in the animals receiving ICV L-NMMA compared with ICV D-NMMA $(20.37 \pm 3.84$ vs. $30.58 \pm 2.38 \mathrm{mg} / \mathrm{kg} / \mathrm{min}, P<0.05)$ (Fig. 8$)$. Plasma glucose response to bolus administration of arginine was identical in both groups of rats (Fig. 7), but serum insulin levels were significantly lower in the rats receiving ICV L-NMMA (Fig. 9).
Peak insulin concentrations occurred at $1 \mathrm{~min}$ and were markedly reduced in L-NMMA - versus D-NMMA-infused animals $(145.3 \pm 33.9$ vs. $251.4 \pm 105.3 \mu \mathrm{U} / \mathrm{ml}, P<0.05)$. Insulin areas under the curve above basal levels following arginine administration were lower in L-NMMA compared with D-NMMA ICVinfused animals (1227 \pm 231 vs. $2504 \pm 837$, respectively, $P=0.06)$.

\section{Discussion}

The current study was designed to evaluate the role of CNS NOS activity on glucose and insulin homeostasis in conscious chronically-catheterized rats. The novel findings of this study are that acute inhibition of CNS NOS induces: hyperglycemia, insulin resistance, defective insulin secretion, and hypertension. These abnormalities recapitulate the cardinal features of overt type 2 diabetes and some features of the insulin-resistance syndrome $(12,20)$. The data suggest that central nitrergic neuronal pathways could be involved in regulating and maintaining glucose homeostasis, and that abnormalities in these pathways could play a role in the etiopathogenesis of certain forms of insulin resistance and type 2 diabetes.

L-NMMA is a competitive inhibitor of the enzyme NOS (21). We have previously shown that when given in large doses (15 $\mathrm{mg} / \mathrm{kg}$ ) to rats peripherally, L-NMMA acutely causes marked hypertension and insulin resistance (15). Given that L-NMMA inhibits all forms of NOS and that knockout mice for both nNOS (a gene product of NOS I) and eNOS (a gene product of NOS III) exhibit sustained hypertension $(22,23)$,

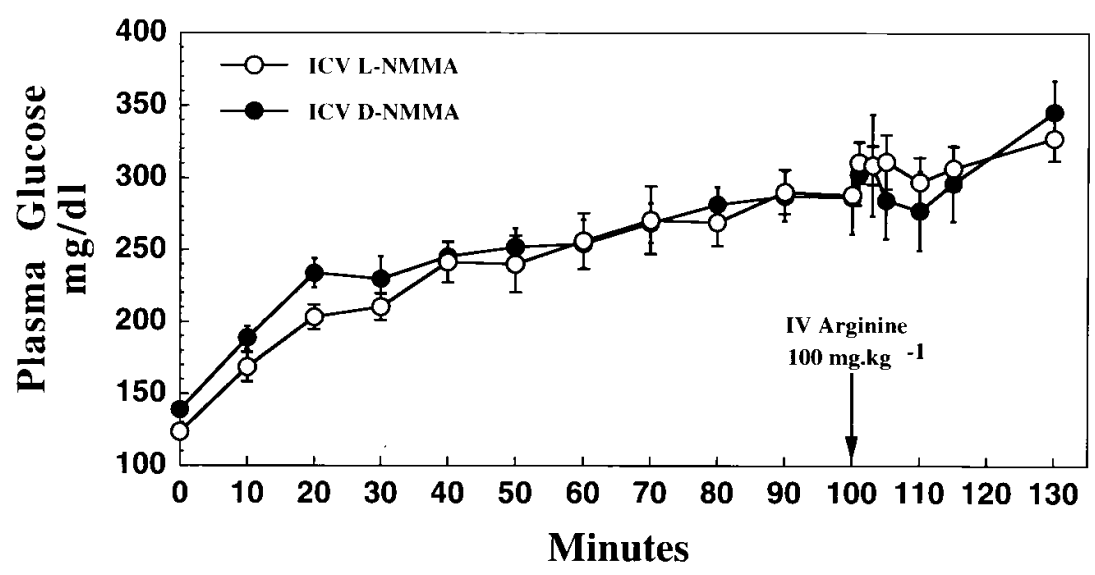

Figure 7. Plasma glucose concentrations in rats during a hyperglycemic clamp study performed after ICV administration of L-NMMA or D-NMMA and following an arginine stimulation test (protocol 3). 


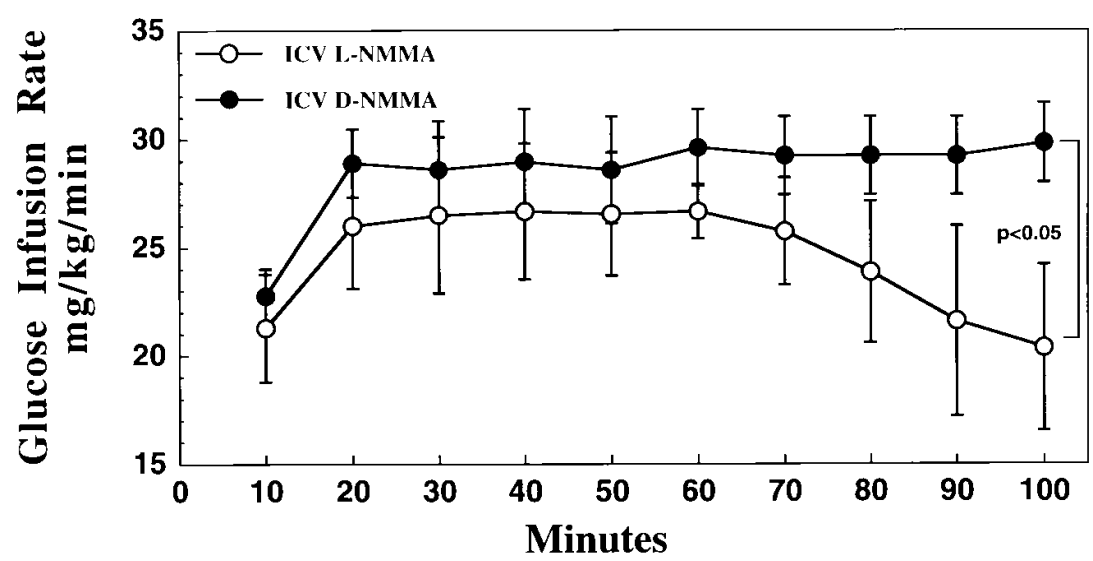

Figure 8 . GIRs $(\mathrm{mg} / \mathrm{kg} / \mathrm{min})$ in rats during a hyperglycemic clamp study performed after ICV administration of either L-NMMA or D-NMMA and following an arginine stimulation test (protocol 3). we wished to test whether specific inhibition of NOS activity resident in the CNS could cause insulin resistance. Because systemic infusion of $500 \mu \mathrm{g}$ of L-NMMA had no effect on blood glucose or blood pressure (Table II), it is highly likely that in the current study all the effects observed following ICV infusion of the same dose of L-NMMA are secondary to acute inhibition of NOS isoforms that reside in the CNS. Of course, the predominant NOS isoform in the CNS is nNOS, and, therefore, it is likely that the physiologic changes observed are the result of inhibition of nNOS. However, brain microvessels express eNOS, and one cannot exclude the possibility that inhibition of this isoform also contributed in part to the overall effect.

Elevation of blood pressure was rapid following ICV infusion of L-NMMA. The maximal pressor effect was noted within minutes and was sustained for the 2-h period of observation. Previous studies have noted that acute inhibition of nNOS in rats results in hypertension (24-27). The nNOS knockout mouse is markedly hypertensive, confirming and further strengthening these findings (23). The exact mechanism(s) by which hypertension is induced by nNOS inhibition is not entirely clear, but an increase in sympathetic outflow, in particular renal sympathetic activity, has been strongly implicated, suggesting that CNS NOS activity tonically inhibits sympathetic outflow (28). To assess overall sympathetic nervous system activity, we measured serum catecholamine levels during CNS NOS blockade and found no change in these hor- mone levels over control. However, serum catecholamines are not very sensitive indicators of local sympathetic nerve activity (29-31) and thus, we cannot rule out that changes in CNS sympathetic outflow were not instrumental in causing hypertension via increases in regional sympathetic activity $(28,32)$. It is important to note that ICV infusions of either D-NMMA or L-NMMA in our study had no apparent effect to increase circulating epinephrine levels, suggesting that the ICV infusion technique employed was not itself perceptibly stressful. It should be noted, however, that catecholamine levels displayed a great degree of variability, and thus, it is possible that we did not detect subtle but physiologically significant changes in catecholamine levels. Very recently, Uemura et al. reported the onset of hyperglycemia following L-NMMA infusion into the third ventricle of albino Wistar rats (33). The authors examined doses of L-NMMA spanning the one used in our study and observed a rapid rise in blood glucose concentrations, reaching a peak at 15-30 min and returning to baseline by 60 min. At a dose two times larger than the one used in our study, they noted transient elevations of circulating concentrations of epinephrine and norepinephrine. Elevations of the former could have accounted for the hyperglycemia observed via its effects to cause peripheral insulin resistance and insulin secretory defects $(34,35)$. Interestingly, Uemura et al. (33) also noted paradoxical elevations of circulating glucagon concentrations in the face of hyperglycemia and could prevent hyperglycemia induced by central NOS blockade with pretreatment with pe-

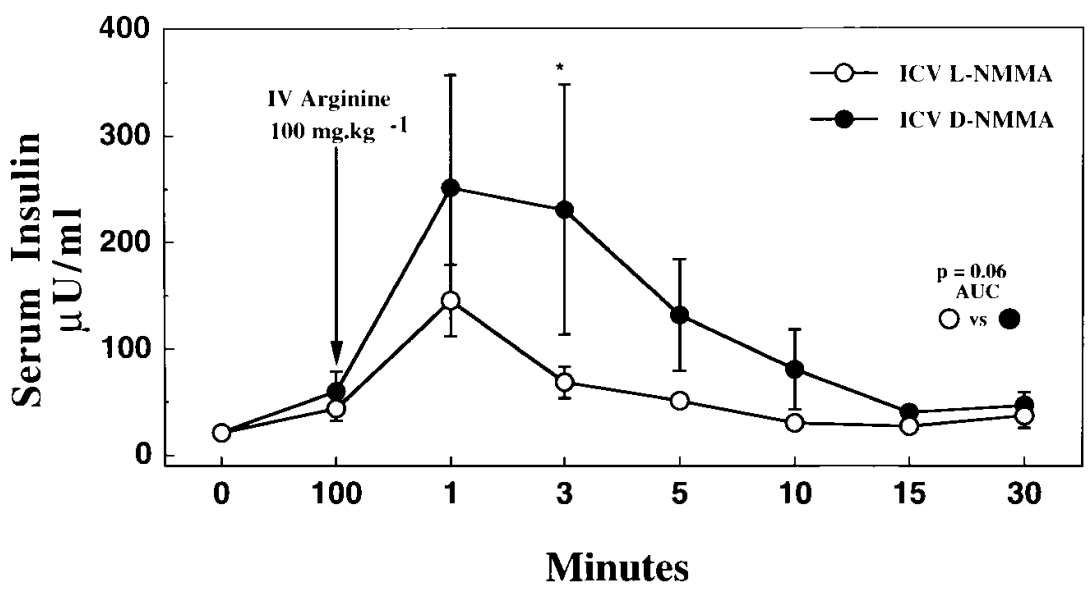

Figure 9. Serum insulin levels during a hyperglycemic clamp study performed after ICV administration of either L-NMMA or D-NMMA and following an arginine stimulation test (protocol 3). $* P<0.05$. 
ripheral alpha adrenergic blockade or adrenomedullectomy, but not beta adrenergic blockade. No measures of blood pressure were reported. They concluded that central NO-dependent neural pathways could be instrumental in causing hyperglycemia via effects on pancreatic and adrenomedullary hormone secretion. Our current findings support their conclusions only in part. Indeed, we did not observe any increases in circulating concentrations of either epinephrine or norepinephrine. Moreover, at similar doses of L-NMMA, the rise in blood glucose observed in our study was gradual and sustained over the 2-h observation period rather than transient. Experimental differences are likely to account for these apparently divergent observations. In addition to the lower dose of L-NMMA used, we also used artificial CSF and a smaller infusion volume ( 2 vs. $5 \mu \mathrm{l}$ ) administered over $6 \mathrm{~min}$, which may have also minimized catecholamine release. Therefore, our data do not suggest that hyperglycemia induced by central NOS blockade is caused by epinephrine release but via another mechanism(s).

Our results suggest that hyperglycemia induced by central blockade of NOS results from two separate and important abnormalities. First, as we had previously observed with peripheral administration of L-NMMA (15), central NOS blockade acutely induced a significant degree of insulin resistance. This was most evident at the level of peripheral tissues where insulin-stimulated glucose uptake was reduced by $26 \%$. Although less marked, insulin resistance was also evident at the level of the liver as hyperinsulinemia was unable to suppress completely endogenous glucose production, as was the case during ICV administration of D-NMMA. As previously reported, L-NMMA-induced insulin resistance is coincident with the onset of hypertension (14), and thus, one could speculate that insulin resistance is etiologically related to hypertension in this model. However, it is well established that many forms of hypertension are not associated with insulin resistance. Indeed, the spontaneously hypertensive rat (36), the transgenic hypertensive REN-2 rat (37), and the two-kidney one-clip rat model of hypertension (38), as well as angiotensin II (39) or norepinephrine (40) infusion in humans, are not associated with insulin resistance. Therefore, while it is possible that insulin resistance and hypertension are etiologically related in our model, it is more likely that they are caused separately by a common mechanism related to central NOS inhibition. If insulin resistance was the only abnormality induced by central NOS blockade, one would not expect a significant rise in the fasting glucose concentration because of the expected compensatory hyperinsulinemia secondary to $\beta$-cell hypersecretion. During CNS NOS blockade, insulin concentrations remained inappropriately unchanged in the face of hyperglycemia, suggesting abnormalities in glucose-induced insulin secretion. Second, an abnormal insulin secretory response to glucose was confirmed with the use of the hyperglycemic clamp. Indeed, during hyperglycemia, insulin levels were similar in D-NMMA- and L-NMMA-infused groups when one would expect insulin levels to be much higher in the insulin-resistant (L-NMMAinfused) group. Moreover, this insulin secretory abnormality was shown to extend to nonglucose secretagogues, such as arginine. Finally, it is unlikely that alterations in insulin clearance accounted for the differences in insulin concentrations because steady-state insulin levels during the hyperinsulinemic euglycemic clamp studies were similar in D-NMMA- and L-NMMA-infused groups. Therefore, our data suggest that in- hibition of NOS in the CNS results in peripheral tissue (and perhaps hepatic) insulin resistance and defective insulin secretion in response to both glucose and nonglucose secretagogues, all classic pathophysiologic features of type 2 diabetes.

The mechanism(s) by which acute inhibition of central NOS results in $\beta$-cell dysfunction and insulin resistance remains speculative at this point. Certainly, the pancreatic islet is richly innervated by vagal adrenergic and cholinergic neurons $(41,42)$. In addition, the vagus carries so-called nonadrenergic, noncholinergic (NANC) neurons containing NO-nitrergic fibers $(43,44)$. Neurons containing NO have been described in the pancreatic islets tissue of both rats and humans (45). Likewise, NANC neurons have been described in skeletal muscle and its vasculature $(46,47)$. Thus, it is conceivable that nitrergic neurons project from the CNS to the pancreas to modulate insulin secretion and to skeletal muscle to modulate insulin action. Alternatively, it is possible that central NO-dependent neural pathways control hypothalamic/pituitary release of hormones, which in turn acutely modulate insulin secretion and insulin action. These possibilities deserve further study.

With the discovery of leptin (48) and other centrally acting factors that modulate satiety and/or energy expenditure, it has become clear that CNS can be an etiologic site for the development of obesity but also for the induction of type 2 diabetes in animal models displaying susceptible genetic backgrounds (48). Over the last decade, Jeanrenaud and colleagues have championed the idea that a search for initiating events in the pathophysiology of both obesity and type 2 diabetes should be focused on the CNS $(49,50)$. Most animal models of type 2 diabetes are obese, such as the Zucker diabetic fatty rat and the $d b / d b$ mouse (both exhibit leptin receptor mutations) (51-54), and thus, diabetes in those models has largely been attributed to the failure of the $\beta$-cell to compensate for the insulin resistance that accompanies accumulation of fat mass. Peripheral administration of leptin has recently been reported to acutely (55) increase in vivo insulin sensitivity independent of changes in fat mass. More recently, the action of leptin to increase peripheral insulin sensitivity was defined to perhaps have a CNS origin (56). Subacute ICV leptin administration was potent at enhancing insulin sensitivity in skeletal muscle of mice, independent of any changes in body weight, and muscle denervation was apparently able to abolish this effect (56). Together, these data suggest the possibility that leptin deficiency or lack of central leptin effect can be associated with reduced peripheral insulin action, independent of changes in fat mass. Our rat model of type 2 diabetes shares a CNS etiology with animal models exhibiting reduced leptin action, but differs significantly in that our model is lean and the onset of the diabetes is acute. Speculatively, it is tempting to suggest that perhaps one of the efferent signal(s) triggered by leptin in the CNS may be nitrergic in nature, and that defects in this efferent signal could result in insulin resistance and defective insulin secretion.

In summary, we report for the first time the acute onset of hyperglycemia secondary to defects in insulin secretion and insulin action following inhibition of CNS NOS activity. These alterations in glucose homeostasis are not likely attributable to changes in circulating concentrations of catecholamines and, therefore, the data suggest that central NANC efferent pathways may control glucose homeostasis. The data further suggest that dysfunction of CNS NO-dependent neural pathways may play an instrumental role in the etiopathogenesis of certain forms of insulin resistance and type 2 diabetes. 


\section{Acknowledgments}

The authors wish to thank Ginger Hook and Joyce Ballard for their assistance in the preparation of the manuscript.

This work was supported by research grants DK42469 and DK20452 from the National Institutes of Health and a Veterans Affairs Merit Review Award.

\section{References}

1. Robertson, R.P. 1992. Defective insulin secretion in NIDDM: integral part of a multiplier hypothesis. J. Cell. Biochem. 48:227-233. (Review.)

2. Leahy, J.L. 1990. Natural history of p-cell dysfunction in NIDDM. Diabetes Care. 13:992-1010.

3. Polonsky, K.S., J. Sturis, and G.I. Bell. 1996. Non-insulin-dependent diabetes mellitis-A genetically programmed failure of the beta cell to compensate for insulin resistance. N. Engl. J. Med. 334:777-783.

4. Kolterman, O.G., R.S. Gray, J. Griffin, P. Burstein, J. Insel, J.A. Scarlett, and J.M. Olefsky. 1981. Receptor and postreceptor defects contribute to insulin resistance in non-insulin dependent diabetes mellitus. J. Clin. Invest. 68:957-969.

5. DeFronzo, R.A., R.C. Bonadonna, and E. Ferrannini. 1992. Pathogenesis of NIDDM. A balanced overview. Diabetes Care. 15:318-368.

6. Yki-Jarvinen, H. 1994. Pathogenesis of non-insulin-dependent diabetes mellitus. Lancet. 343:91-95.

7. Garvey, W.T., R.R. Revers, O.G. Kolterman, A.H. Rubenstein, and J.M. Olefsky. 1985. Modulation of insulin secretion by insulin and glucose in type II diabetes mellitus. J. Clin. Endocrinol. Metab. 60:559-568.

8. Kahn, C.R., D. Vicent, and A. Doria. 1996. Genetics of non-insulindependent (type-II) diabetes mellitus. Аnпи. Rev. Med. 47:509-531.

9. Moller, D.E., C. Bjorbaek, and A. Vidal-Puig. 1996. Candidate genes for insulin resistance. Diabetes Care. 19:396-400.

10. Barbetti, F. 1996. Pathophysiology of non-insulin-dependent diabetes and the search for candidate genes: dangerous liaisons? Acta Diabetol. 33:257-262.

11. Revers, R.R., R.I. Fink, J. Griffin, J.M. Olefsky, and O.G. Kolterman. 1984. Influence of hyperglycemia on insulin's in vivo effects in type II diabetes. J. Clin. Invest. 73:664-672.

12. DeFronzo, R.A. 1988. The triumvirate: beta-cell, muscle, liver. A collusion responsible for NIDDM. Diabetes. 37:667-687.

13. Kolterman, O.G., R.S. Gray, G. Shapiro, J.A. Scarlett, J. Griffin, and J.M. Olefsky. 1984. The acute and chronic effects of sulfonylurea therapy in type II diabetic subjects. Diabetes. 33:346-354.

14. Ignarro, L.J. 1990. Nitric oxide. A novel signal transduction mechanism for transcellular communication. Hypertension. 16:477-483.

15. Baron, A.D., J. Zhu, S. Marshall, O. Irsula, G. Brechtel, and C. Keech. 1995. Insulin resistance following acute induction of hypertension with the nitric oxide synthesis inhibitor L-NMMA in rats. Am. J. Physiol. 269:E709-E715.

16. Paxinos, G., and C. Watson. 1986. Atlas of Paxinos and Watson. Academic Press, Inc., San Diego.

17. Baron, A.D., J.-S. Zhu, J.-H. Zhu, H. Weldon, L. Maianu, and W.T. Garvey. 1995. Glucosamine induces insulin resistance in vivo by affecting GLUT 4 translocation in skeletal muscle. J. Clin. Invest. 96:2792-2801.

18. Smith, D., L. Rossetti, E. Ferrannini, C.M. Johnson, C. Cobelli, G. Toffolo, L.D. Katz, and R.A. DeFronzo. 1987. In vivo glucose metabolism in the awake rat: tracer and insulin clamp studies. Metabolism. 36:1167-1174.

19. Boren, D.R., D.P. Henry, E.E. Selkurt, and M.H. Weinberger. 1980. Renal modulation of urinary catecholamine excretion during volume expansion in the dog. Hypertension. 2:383-389.

20. Reaven, G.M. 1988. Role of insulin resistance in human disease. Diabetes. 37:1595-1607.

21. Moncada, S., R.M.J. Palmer, and E.A. Higgs. 1989. Biosynthesis of nitric oxide from L-arginine: a pathway for the regulation of cell function and communications. Biochem. Pharmacol. 11:1709-1715.

22. Huang, P.L., Z. Huang, H. Mashimo, K.D. Bloch, M.A. Moskowitz, J.A. Bevan, and M.C. Fishman. 1995. Hypertension in mice lacking the gene for endothelial nitric oxide synthase. Nature. 377:239-242.

23. Huang, P.L., T.M. Dawson, D.S. Bredt, S.H. Snyder, and M.C. Fishman. 1993. Targeted disruption of the neuronal nitric oxide synthase gene. Cell. 75: 1273-1286.

24. Gerova, M., C. Masanova, and J. Pavlasek. 1995. Inhibition of NO synthase in the posterior hypothalamus increases blood pressure in the rat. Physiol. Res. 44:131-134.

25. Shapoval, L.N., V.F. Sagach, and L.S. Pobegailo. 1991. Nitric oxide influences ventrolateral medullary mechanisms of vasomotor control in the cat. Neurosci. Lett. 132:47-50.

26. Horn, T., P.M. Smith, B.E. McLaughlin, L. Bauce, G.S. Marks, and A.V. Ferguson. 1994. Nitric oxide actions in paraventricular nucleus: cardiovascular and neurochemical implications. Am. J. Physiology. 266:R306-R313.

27. Nurminen, M.L., A. Ylikorkala, and H. Vapaatalo. 1997. Central inhibi- tion of nitric oxide synthesis increases blood pressure and heart rate in anesthetized rats. Methods Find. Exp. Clin. Pharmacol. 19:35-41.

28. Harada, S., S. Tokunaga, M. Momohara, H. Masaki, T. Tagawa, and A. Takeshita. 1993. Inhibition of nitric oxide formation in the nucleus tractus solitarius increases renal sympathetic nerve activity in rabbits. Circ. Res. 72:511-516.

29. Thomas, J., F.M. Fouad, R.C. Tarazi, and E.L. Bravo. 1983. Evaluation of plasma catecholamines in humans. Correlation of resting levels with cardiac responses to beta-blocking and sympatholytic drugs. Hypertension. 5:858-863.

30. Goldstein, D.S., G. Eisenhofer, M. Garty, C.J. Folio, R. Stull, Jr., F.L. Sax, H.R. Keiser, and I.J. Kopin. 1989. Implications of plasma levels of catechols in the evaluation of sympathoadrenomedullary function. Am. J. Hypertens. 2:133S-139S

31. Mancia, G., and G. Grassi. 1991. Assessment of sympathetic cardiovascular influences in man: haemodynamic and humoral markers versus microneurography. Clin. Auton. Res. 1:245-249.

32. Hirai, T., T.I. Musch, D.A. Morgan, K.C. Kregel, D.E. Claassen, J.G. Pickar, S.J. Lewis, and M.J. Kenney. 1995. Differential sympathetic nerve responses to nitric oxide synthase inhibition in anesthetized rats. Am. J. Physiol. Regul. Integr. Comp. Physiol. 269:R807-R813.

33. Uemura, K., T. Tamagawa, Y. Chen, N. Maeda, S. Yoshioka, K. Itoh, H. Miura, A. Iguchi, and N. Hotta. 1997. $N^{\mathrm{G}}$-methyl-L-arginine, an inhibitor of nitric oxide synthase, affects the central nervous system to produce peripheral hyperglycemia in conscious rats. Neuroendocrinology. 66:136-144.

34. Beard, J.C., C. Weinberg, M.A. Pfeifer, J.D. Best, J.B. Halter, and D. Porte, Jr. 1983. Modulation of arginine-induced glucagon release by epinephrine and glucose levels in man. J. Clin. Endocrinol. Metabolism. 56(6):12711277.

35. Porte, Jr., D., and R.P. Robertson. 1973. Control of insulin secretion by catecholamines, stress, and the sympathetic nervous system. Federation Proc. 32:1792-1796.

36. Buchanan, T.A., G.F. Sipos, N. Madrilejo, C. Liu, and V.M. Campese. 1992. Hypertension without peripheral insulin resistance in spontaneously hypertensive rats. Am. J. Physiol. 262:E14-E19.

37. Vettor, R., I. Cusin, D. Ganten, F. Rohner-Jeanrenaud, E. Ferrannini, and B. Jeanrenaud. 1994. Insulin resistance and hypertension: studies in transgenic hypertensive TGR(mREN-2)27 rats. Am. J. Physiol. Regul. Integr. Comp. Physiol. 267:R1503-R1509.

38. Frontoni, S., L. Ohman, J.R. Haywood, and L. Rossetti. 1992. Increased insulin sensitivity in high sodium one kidney, one figure-8 hypertensive rat. $\mathrm{Hy}$ pertension. 20:192-198.

39. Buchanan, T.A., H. Thawani, W. Kades, J.G. Modrall, F.A. Weaver, C. Laurel, R. Poppili, A. Xiang, and W. Hsueh. 1993. Angiotensin II increases glucose utilization during acute hyperinsulinemia via a hemodynamic mechanism. J. Clin. Invest. 92:720-726.

40. Baron, A.D., G. Brechtel, A. Johonson, N. Fineberg, D.P. Henry, and H.O. Steinberg. 1994. Interactions between insulin and norepinephrine on blood pressure and insulin sensitivity. Studies in lean and obese men. J. Clin. Invest. 93:2453-2462.

41. Ahren, B., G.J. Taborsky, Jr., and D. Porte, Jr. 1986. Neuropeptidergic versus cholinergic and adrenergic regulation of islet hormone secretion. Diabetologia. 29:827-836.

42. Woods, S.C., and D. Porte, Jr. 1974. Neural control of the endocrine pancreas. Physiol. Rev. 54:596-619.

43. Rich, S.S. 1990. Mapping genes in diabetes. Genetic epidemiological perspective. Diabetes. 39:1315-1319.

44. Krowicki, Z.K., K.A. Sharkey, S.C. Serron, N.A. Nathan, and P.J. Hornby. 1997. Distribution of nitric oxide synthase in rat dorsal vagal complex and effects of microinjection of nitric oxide compounds upon gastric motor function. J. Comp. Neurol. 377:49-69.

45. Worl, J., M. Wiesand, B. Mayer, K.R. Greskotter, and W.L. Neuhuber. 1994. Neuronal and endothelial nitric oxide synthase immunoreactivity and NADPH-diaphorase staining in rat and human pancreas: influence of fixation. Histochemistry. 102:353-364.

46. Berdeaux, A. 1993. Nitric oxide: an ubiquitous messenger. Fundam. Clin. Pharmacol. 7:401-411.

47. Possas, O.S., and S.J. Lewis. 1997. NO-containing factors mediate hindlimb vasodilation produced by superior laryngeal nerve stimulation. Am. $J$. Physiol. 273:H234-H243.

48. Zhang, Y., R. Proenca, M. Maffei, M. Barone, and L. Leopold. 1994. Positional cloning of the mouse obese gene and its human homologue [published erratum appears in Nature 1995 Mar 30;374(6521):479]. Nature. 372:425-432.

49. Jeanrenaud, B. 1994. Central nervous system and peripheral abnormalities: clues to the understanding of obesity and NIDDM. Diabetologia. 37(Suppl. 2):S170-S178.

50. Blasi, C., and B. Jeanrenaud. 1993. Insulin resistance syndrome: defective GABA neuromodulation as a possible hereditary pathogenetic factor (the GABA hypothesis). Med. Hypotheses. 40:197-206.

51. Phillips, M.S., Q. Liu, H.A. Hammond, V. Dugan, P.J. Hey, C.J. Caskey, and J.F. Hess. 1996. Leptin receptor missense mutation in the fatty Zucker rat. Nat. Genet. 13:18-19.

52. Takaya, K., Y. Ogawa, N. Isse, T. Okazaki, N. Satoh, H. Masuzaki, K. Mori, N. Tamura, K. Hosoda, and K. Nakao. 1996. Molecular cloning of rat lep- 
tin receptor isoform complementary DNAs-identification of a missense mutation in Zucker fatty (fa/fa) rats. Biochem. Biophys. Res. Commun. 225(1):75-83.

53. Lee, G.-H., R. Proenca, J.M. Montez, K.M. Carroll, J.G. Darvishzadeh, J.I. Lee, and J.M. Friedman. 1996. Abnormal splicing of the leptin receptor in diabetic mice. Nature. 379:632-635.

54. Chen, H., O. Charlat, L.A. Tartaglia, E.A. Woolf, X. Weng, S.J. Ellis, N.D. Lakey, J. Culpepper, K.J. Moore, R.E. Breitbart, G.M. Duyk, R.I. Tepper, and J.P. Morgenstern. 1996. Evidence that the diabetes gene encodes the leptin receptor: identification of a mutation in the leptin receptor gene in $d b / d b$ mice. Cell. 84:491-495.

55. Sivitz, W.I., S.A. Walsh, D.A. Morgan, M.J. Thomas, and W.G. Haynes. 1997. Effects of leptin on insulin sensitivity in normal rats. Endocrinology. 138: 3395-3401.

56. Kamohara, S., R. Burcelin, J.L. Halaas, J.M. Friedman, and M.J. Charron. 1997. Acute stimulation of glucose metabolism in mice by leptin treatment. Nature. 389:374-377. 